\title{
Valor do Gradiente de Pressão Retal e Anal na Evacuação em Megacólon Adquirido
}

\author{
Rectal and Anal Pressure Variation During Defecation in Patients \\ with Acquired Megacolon
}

\author{
CHIABINFANG ${ }^{1}$; WILMAR ARTUR KLUG ${ }^{2}$; HELLYANGELACARAM AGUIDA ${ }^{3}$; \\ JORGEALBERTO ORTIZ; ${ }^{3}$ PERETZCAPELHUCHNIK ${ }^{2}$
}

${ }^{1}$ Professor Associado, Doutor em Cirurgia; ${ }^{2}$ Professor Titular; ${ }^{3}$ Mestre em Cirurgia.

\begin{abstract}
FANG CB; KLUG WA; AGUIDA HAC; ORTIZ JA; CAPELHUCHNIK P. Valor do gradiente de pressão retal e anal na evacuação em megacólon adquirido. Rev bras Coloproct, 2007;27(3): 264-268.

RESUMO: O megacólon resulta de lesão extensa dos plexos mioentéricos, a qual se traduz por incoordenação motora do cólon com inércia funcional e acalasia do esfíncter anal. Disso resulta duplo distúrbio, em que à dificuldade motora agrega-se o obstáculo para evacuar. Para que haja eliminação fecal é necessário que a pressão retal ultrapasse a anal, havendo um gradiente reto-anal. $O$ objetivo do trabalho foi avaliar este gradiente em 29 pacientes portadores de megacólon, em que as pressões retais e anais foram medidas ao evacuar, comparadas com pessoas normais. Os resultados mostraram que havia pressão retal em centímetros de água aumentada em homens $(\mathbf{7 2 , 2} \pm \mathbf{2 9 , 1})$ e mulheres $(64,5 \pm 20,1)$, superando as respectivas pressões anais de evacuação $(66,4 \pm 23,2$ e 62,1 $\pm 28,7)$. As pressões de evacuação, por sua vez, eram muito maiores que as do grupo controle. Isto permitiu concluir haver uma reação adaptativa com maior esforço muscular para evacuar, a fim de superar o obstáculo da acalasia.
\end{abstract}

Descritores: megacólon, manometria, acalasia, defecação, esfíncter anal.

\section{INTRODUÇÃO}

Acredita-se que cerca de $4 \%$ dos doentes portadores da Doença de Chagas, sejam acometidos por megacólon. Adoença inicia muitos anos após a inoculação e caracteriza-se por constipação progressiva, de início tratada com laxativos. Com a progressão da moléstia estes medicamentos tornam-se insuficientes, tendo-se de recorrer a clisteres para obter evacuação satisfatória. Neste período sobrevêm complicações, como os volvos e a formação de fecalomas. A existência delas é que leva a indicar a cirurgia como forma preferencial de tratamento.

Há tempos são conhecidas as alterações fisiopatológicas mais importantes, mas não foram suficientemente divulgadas para dar uma compreensão global do problema. Assim, são descritas as lesões dos plexos mioentéricos, que afetam extensões variáveis do cólon e reto, e determinam alterações funcionais caracterizadas por hiperexcitabilidade das fibras musculares da parede do intestino e discinesia. A alteração motora determina estase por defeito de propulsão, dilatação, hipertrofia muscular e da própria víscera. Além desses afeitos, descreve-se a acalasia do esfíncter interno do ânus, que causa obstáculo à evacuação por falta de relaxamento anal no momento da exoneração. Estas alterações são de conhecimento antigo e foram descritas por diversos autores ${ }^{1,2,3,4}$.

A evidência clínica e manométrica da acalasia levou a uma série de tentativas terapêuticas, com vários procedimentos cirúrgicos destinados a remover o empecilho representado pelo ânus não relaxável ao esforço de evacuação. Propôs-se tratar do distúrbio

Trabalho realizado na Disciplina de Coloproctologia do Departamento de Cirurgia da Faculdade de Ciências Médicas da Santa Casa de São Paulo. 
funcional anal por esfincterotomia pelve-retal, dilatações anais forçadas manuais ou instrumentais, ano-retomiotomia com diferentes extensões. Estes procedimentos foram sendo paulatinamente abandonados. As razões para tanto decorreram da falta de resultados funcionais satisfatórios após as operações. Algumas vezes praticaram-se processos combinados anais e colo-retais, com ressecções associadas a tratamentos sobre o ânus, com resultados variáveis e dependentes do tipo de casuística relacionada. Em vista dos fracassos dos procedimentos especificamente sobre o ânus, ficou clara a importância de outros fatores. Ressalta-se a importância fundamental da discinesia do reto e sigmóide, quando não de todo o cólon. Estas alterações funcionais, em conjunto podendo ser denominadas como inércia do cólon, passaram a ter cada vez maior importância. Disso resultou uma série de operações de ressecção do reto e sigmóide, ou segmentos ainda mais alargados do cólon, a fim de corrigir a discinesia ou inércia. A partir de reto-sigmoidectomias que visavam o segmento retal e sigmoideano, considerados mais afetados pelo dano da inervação, chegou-se a realizar colectomias mais extensas ${ }^{5,6}$.

Atualmente fica claro que o problema fisiopatológico do megacólon adquirido reside em uma dupla alteração. Há a inércia do cólon associada à acalasia do ânus, combinados de forma variável e somente quantificáveis por métodos modernos de medida manométrica e funcional. É também evidente que o tratamento deve atender às duas condições patológicas básicas.

No que se refere à acalasia, novos estudos fisiológicos se impõem, pois os conhecimentos do distúrbio funcional ainda apresentam incertezas ${ }^{7,8}$. Entre elas o conceito do gradiente de pressão reto-anal, como a relação entre as pressões intra-retais e do canal anal à evacuação. Tal conceito se justifica, pois a evacuação só será possível se no momento da exoneração a pressão retal for superior à anal. Ora, o reto de paciente com megacólon, amplo e complacente, sem atividade motora coordenada, age como bolsa com conteúdo aéreo e fecal, inativa. A exoneração somente será efetivada quando a pressão intra-retal, desencadeada por forte contração da parede abdominal, superar a pressão anal de evacuação.

\section{OBJETIVO}

O objetivo do estudo é verificar quais as pressões retais e anais obtidas em pacientes chagásicos com megacólon avançado, a fim de verificar se as pres- sões intra-retais no momento da evacuação podem superar as anais no mesmo instante, de modo a haver uma razão maior que 1 entre estas medidas. $O$ gradiente reto-anal, por conseguinte, mede a capacidade de vencer a acalasia e mede, nestes casos, um dos distúrbios funcionais mais importantes.

\section{BASES FISIOPATOLÓGICAS DO ESTUDO}

Durante a evacuação de um indivíduo normal, as fezes são depositadas no reto por grandes movimentos peristálticos de massa, que projetam o material na luz retal quase virtual, a não ser por pequenos volumes residuais fecais ou de gases. Esta deposição determina sensações perceptíveis e reflexas, a partir de um volume em torno de $50 \mathrm{ml}$. Com o aumento do conteúdo, a sensação passa a ser constante. Para que estes fenômenos sejam percebidos pela consciência, deve haver integridade de vias nervosas, que a partir de receptores nas paredes, levam os estímulos ao encéfalo. A sensação de desejo de evacuar, portanto, depende de integridade nervosa. Ao contrair-se a parede do abdome no momento da evacuação, a pressão intra-retal atinge níveis altos e o ânus relaxa reflexamente. A evacuação ocorre a seguir pela abertura do canal anal. Ora, nos portadores de megacólon as vias nervosas estão destruídas, de modo que não há respostas fisiológicas normais. A complacência é muito maior. Não há sensação definida de desejo de evacuar e o reflexo reto-anal pode estar abolido. Não há relaxamento esfincteriano reflexo (acalasia). Em conseqüência, a evacuação se processa por um modelo simples de aumento da pressão intra-retal, secundária à contração da parede abdominal, que necessariamente deverá superar a pressão anal à evacuação.

\section{CASUÍSTICA E MÉTODO}

Vinte e nove doentes, 19 mulheres e 10 homens, acometidos por megacólon foram incluídos no estudo, enviados para exames de avaliação na área de Fisiologia Anal da Disciplina de Coloproctologia do Departamento de Cirurgia da Santa Casa de São Paulo. Comprovou-se a existência da doença de Chagas e antecedentes de resistência à terapêutica medicamentosa e/ou referência a formação de fecaloma ou volvo. Foi em todos realizada manometria anal por meio de aparelho portátil munido de balão preenchido por água. O registro gráfico foi obtido por transdutor, 
que transmitia a energia física da compressão do balão de látex ,com $0,5 \mathrm{~cm}$ de diâmetro, a um registrador gráfico digital. As medidas obtidas representam centímetros de água. Mediram-se, sem preparo especial do cólon, as pressões retais e anais no momento da simulação do esforço de evacuar. Cada medida era repetida três vezes a cada centímetro, por tração da sonda desde $6 \mathrm{~cm}$ (reto) até a região determinada como de maior pressão de repouso no canal anal. Neste local avaliou-se a menor pressão obtida durante o esforço de evacuação, para medir o relaxamento fisiológico produzido pelo ato de evacuar. Em cada ponto de parada foram realizadas três medidas, considerando-se para cálculo a maior pressão no reto (capacidade de expulsão) e a menor no canal anal (relaxamento). Para comparar os valores com um padrão de normalidade, foram utilizados os dados obtidos por Aguida $^{9}$ que examinou 60 homens e 60 mulheres sem doença colo-retal.

\section{RESULTADOS}

As pressões retais e anais à evacuação encontradas estão relacionadas nas tabelas 1 a 4 , onde se comparam os grupos submetidos à análise e as medidas de pressão. Os valores encontrados foram submetidos à análise estatística, aplicando-se o teste t de Student, considerando-se 0,05 como índice de significância.

Foram comparados os grupos amostrais de portadores de megacólon e o grupo controle, separados por sexo e assinaladas as respectivas médias de idade (Tabela 1). A seguir foram comparadas em conjunto as pressões retais (capacidade de expulsão) e anais (relaxamento) no momento da evacuação de todos os 29 doentes, observando-se consideráveis diferenças entre o grupo de megacólon e controle (Tabela 2). Fica claro que a pressão retal à evacuação $(\mathrm{p}=0,01)$ e a pressão anal são muito maiores no grupo megacólon. Os valores significam que não há, em média, relaxamento anal à evacuação, indicativo da acalasia $(\mathrm{p}=0,000)$. No grupo controle a pressão de evacuação é significativamente mais baixa. As pressões retais à evacuação foram maiores entre as mulheres com megacólon e o grupo controle $(\mathrm{p}=0,009)$, e a diferença entre as pressões de evacuação foram evidentes $(\mathrm{p}=0,000)$ (Tabela 3). Da mesma maneira entre os homens, onde as pressões retais e anais foram nitidamente maiores no grupo de portadores do megacólon $(\mathrm{p}=0,025)$, ficou claro o esforço necessário para vencer a falta de relaxamento à evacuação (Tabela 4).

\section{DISCUSSÃO}

As medidas de pressão intra-luminal e anal em pacientes com megacólon adquirido já foram motivo de estudos ${ }^{7}$, visto que o bom conhecimento da fisiopatologia permitiria melhor tratar os doentes. Daí decorre o conceito da dupla alteração funcional: a) o cólon com discinesia, hipertrofia muscular, alongado, dilatado, sem peristaltismo adequado e funcionalmente

Tabela 1 - Casuística considerada para análise pela área de Fisiologia Anal.

\begin{tabular}{lrrrr}
\hline Grupos & \multicolumn{1}{c}{$\mathbf{N}^{\mathbf{0}}$} & \multicolumn{1}{c}{ Idade } & Fem & Masc \\
\hline Megacólon & 29 & 50,3 & 19 & 10 \\
Controle & 120 & 49,7 & 60 & 60 \\
\hline
\end{tabular}

Tabela 2 - Médias das pressões obtidas pela manometria no conjunto de doentes chagásicos e do grupo controle, ao esforço para evacuar $\left(\mathrm{cm} / \mathrm{H}_{2} \mathrm{O}\right)$.

\begin{tabular}{lcc}
\hline & pressão retal & pressão anal \\
\hline Megacólon & $72,2 \pm 29,1$ & $66,4 \pm 23,2$ \\
Controle & $56,7 \pm 26,4$ & $37,8 \pm 16,3$ \\
\hline & $\mathrm{p}=0,01$ & $\mathrm{p}=0,000$
\end{tabular}

Tabela 3 - Médias das pressões obtidas pela manometria em mulheres portadoras de megacólon e grupo controle $\left(\mathrm{cm} / \mathrm{H}_{2} \mathrm{O}\right)$.

\begin{tabular}{lrr}
\hline & pressão retal & pressão anal \\
\hline Megacólon $(\mathrm{n}=19)$ & $64,5 \pm 20,1$ & $62,1 \pm 28,7$ \\
Controle $(\mathrm{n}=60)$ & $50,9 \pm 18,3$ & $37,3 \pm 13,8$ \\
\hline & $\mathrm{p}=0,009$ & $\mathrm{p}=0,000$
\end{tabular}

Tabela 4 - Médias das pressões obtidas pela manometria em homens portadores de megacólon e grupo controle $\left(\mathrm{cm} / \mathrm{H}_{2} \mathrm{O}\right)$.

\begin{tabular}{lcc}
\hline & pressão retal & pressão anal \\
\hline Megacólon $(\mathrm{n}=10)$ & $85,6 \pm 31,2$ & $74,5 \pm 29,6$ \\
Controle $(\mathrm{n}=60)$ & $62,5 \pm 29,5$ & $38,3 \pm 18,5$ \\
\hline & $\mathrm{p}=0,025$ & $\mathrm{p}=0,000$
\end{tabular}


inerte; b) a inadequada abertura do ânus ao momento da evacuação por falta do reflexo inibitório reto-anal, representando obstáculo adicional à exoneração. Todo o distúrbio fundamenta-se nas lesões nervosas, na parede intestinal e no reto, muito mais extensas que a porção dilatada.

Existem divergências na literatura acerca da fisiopatologia e da melhor forma de tratar o megacólon. Na Santa Casa de São Paulo, desde 1975, preferimos a hemicolectomia esquerda associada a dilatação anal digital, com excelente resultado funcional e baixíssima morbidez e recidivas ${ }^{10}$. Assim, atingimos os dois propósitos terapêuticos. Corrigimos a inércia pela anastomose ao reto do cólon transverso facilmente mobilizável e com conteúdo pastoso fácil de exonerar, e diminuímos a resistência anal à evacuação. Outros preferem a sigmoidectomia com anastomose colo-retal término-lateral, com base na falta de sincronismo de contração sigmóide-retal, incoordenação esta responsável pelo sintoma de constipação e pela alteração anátomo-patológica de dilatação e alongamento da víscera ${ }^{11}$. Há ainda a opção pela via vídeolaparoscópica ${ }^{12}$.

Esta última questão foi objeto de nosso estudo, quando acrescentamos a importância do esforço contrátil abdominal para evacuar, pois sem métodos de manometria ou outros usados em fisiologia ano-retal não há como quantificar adequadamente o problema. Além disso, as tentativas terapêuticas isoladas de dilatação ou miotomia são uma resposta bastante pobre se desconsiderada a intensidade do defeito funcional.

$\mathrm{Na}$ casuística analisada predominaram mulheres, que provavelmente mais se ressentem da dificuldade para evacuar e com quadros clínicos suficientemente intensos, a ponto de serem enviadas para tratamento em instituição hospitalar. A disponibilidade de grupo controle com o mesmo método de medida representou oportunidade única para compreender o problema.
Na tabela 2, fica claro que em seu conjunto os pacientes com megacólon fazem um esforço muito maior no momento de simular evacuação que os pacientes do grupo controle ( $\mathrm{p}=0,01)$; ainda, em vista do dano à inervação, não obtém o relaxamento anal necessário, sendo altamente significativa a diferença nas pressões anais de evacuação $(\mathrm{p}=0,000)$. Quando examinamos separadamente as mulheres, observamos que elas não conseguem elevar a pressão intra-retal ao nível alcançado pelos homens, talvez em decorrência da estrutura muscular da parede abdominal. Os valores médios encontrados de pressão retal são ligeiramente maiores que o necessário para transpor o obstáculo anal, sem diferença significativa (tabela 3). Ressalvamos aqui que as medidas de pressão tomadas no laboratório foram em decúbito lateral esquerdo, impedindo o artifício de comprimir as coxas sobre o abdome, o que favorece o aumento a pressão abdominal. Portanto, em decúbito, a evacuação fica virtualmente impossibilitada em mulheres. Pelo contrário, homens conseguiram um regime de pressão abdominal muito maior (tabela 4), o suficiente para vencer o obstáculo funcional $(\mathrm{p}=0,025)$ mesmo que a pressão anal fosse muito maior que a do grupo controle $(\mathrm{p}=0,000)$.

\section{CONCLUSÃO}

Com base nos resultados, concluímos que o conceito de gradiente reto-anal, baseado no resultado da relação numérica de divisão entre os valores médios da pressão retal e anal demonstra o distúrbio funcional da acalasia. Mostra haver uma relação superior à unidade em homens, por adaptação funcional, e uma dificuldade maior entre as mulheres, com uma relação menor, tornando-as menos capazes de evacuar se não utilizarem artifícios medicamentosos, considerando as condições de evacuação previstas em laboratório.

\footnotetext{
ABSTRACT: Megacolon is the result of an extensive lesion of the mioenteric plexus, with lack of motor coordination and achalasia of the anal sphincter. The motility disorder caused by the muscle contraction problems added to a mechanical obstacle results cause constipation. The defecation rectal pressure increases and reaches its peak with the start of fecal flow, exceeding the anal pressure. The objective of this work was to assess the ratio of rectal / anal pressure on 29 megacolon sufferers, compared to normal subjects. Results have shown that defecation rectal pressure was higher than expected for both men $(72,2 \pm 29,1 \mathrm{~cm}$ water) and women $(64,5 \pm 20,1 \mathrm{~cm}$ water) exceeding the defecation anal pressure $(66,4 \pm 23,2$ and $62,1 \pm 28,7 \mathrm{~cm}$ water, for men and women, respectively). The defecation pressures were much higher than those of the control group, what led to the conclusion that as an adaptive reaction, muscular effort increases to make evacuation possible.
}

Keywords: megacolon, manometry, achalasia, defecation, anal sphincter. 


\section{REFERÊNCIAS}

1. Habr-Gama A Haberkorn S Gama-Rodrigues JJ Raia A Betarello - A manometria ano-reto-cólica- comportamento motor normal e patológico. Arq Gastroent S Paulo 1974; 4: p 201-16.

2. Moreira H - Estudo da atividade motora do coto retal e do colo descendente em paciente chagásicos submetidos às cirurgias Hartmann e de Duhamel. Rev Goiana med 1974; 20: p 125-70.

3. Matos D Oliveira E Pan Chacon J - Eletromanometria anoretal- sua avaliação nos indivíduos normais e naqueles portadores de megacólon chagásico. Rev Col Bras Cir 1981; 7: p 140-5.

4. Fang CB - Manometria anal e proctografia nos doentes com megacólon chagásico. ( Tese de doutoramento) São Paulo: Faculdade de Ciências Médicas da Santa Casa de São Paulo; 1996.

5. Vasconcelos E-Colectomia subtotal e anastomose ceco-retal no tratamento de megacólon do adulto. Rev Hosp Clin Fac Med S Paulo 1964; 19; p 321-4.

6. Capelhuchnik P - Tratamento do megacólon adquirido pela hemicolectomia esquerda. (Tese de livre-docência) São Paulo: Faculdade de Ciências Médicas da Santa Casa de São Paulo; 1975.

7. Fang CB Klug WA Aguida H-AC Ortiz JA Capelhuchnik P Avaliação das pressões anais em doentes com megacólon chagásico. Rev bras Coloproct 1998; 18: p 173-177.
8. Moreira H Moreira JPT Moreira Jr H - Avaliação crítica do tratamento cirúrgico de megacólon chagásico in Castro LP et al - Tópicos em Gastroenterologia-avanços em coloproctologia; Medsi Rio de Janeiro: 2001; pg 403-13.

9. Aguida HAC - Efeitos da idade e do sexo nas pressões do canal anal- estudo manométrico (Tese de mestrado) São Paulo: Faculdade de Ciências Médicas da Santa Casa de São Paulo; 1996.

10. Capelhuchnik P Silva Prado W - Hemicolectomia esquerda no tratamento do megacólon-resultado em 57 casos. Anais do Congresso da International Society of University Colon and Rectal Surgeons: São Paulo;1970.

11. Reis Neto JA Pedroso MA Lupinacci RA Reis Junior JA Ciquini S Lupinacci RM Beani AJ Farah JFM Kagohara OH Simões Neto J Romanholi Neto J - Megacólon adquirido. Perspectivas fisiopatológicas para o tratamento laparoscópico. Rev bras Coloproct 2004; 24(1): p 49-62.

12. Nahas SC Dias AR Dainezi MA Araujo SEA Nahas CSR - A vídeo-cirurgia no tratamento do megacólon chagásico. Rev bras Coloproct 2006; 26(4): p 470-474.

\section{Endereço para correspondência:}

DR. WILMAR ARTUR KLUG

Alameda Ribeirão Preto, no 487 - Ap 103

São Paulo - SP

01331-001

Fone (11) 9869-3166 